\title{
Oral rehydration therapy: an epithelial transport success story
}

\author{
W B GREENOUGH III \\ Division of Geographic Medicine, Johns Hopkins University, Baltimore, USA
}

Oral rehydration therapy prevents death in acute watery diarrhoea except in the most severe $1-3 \%$ of cholera cases. If started at the onset of illness, weakness, orthostasis, muscle cramps, lethargy, and other symptoms of a contracted circulating blood volume are entirely prevented. ${ }^{1}$ Poor countries have rapidly expanded their use of this practical and inexpensive treatment ${ }^{2}$ while it has been largely neglected in wealthy nations in favour of the more hazardous and costly luxury of hospitalisation and intravenous therapy. Improved solutions are now emerging that not only rehydrate patients, but also reduce severity and shorten illness. ${ }^{3}$ To grasp this opportunity basic physiological research on the intestinal transport of amino acids, dipeptides and tripeptides, and clinical studies of solutions which optimise all cotransport pathways and minimise lumenal osmotic forces are needed. Such research should be connected to practical field trials of improved oral rehydration solutions.

Of the origin of oral rehydration therapy it can be said that nothing is discovered unless it is already known. As it is a decisively effective treatment based on ingredients in common foods and drinks, glimpses of benefit have been repeatedly observed in many countries in what may be called 'grandmother solutions'. The earliest recorded reference I have found is from Vedic texts. ${ }^{4}$ All such home solutions take partial and unwitting advantage of the potent cotransport capacity of the intestine which links the absorption of salt, water, and certain solutes. Unfortunately the empirical knowledge embodied in folk remedies before the scientific discovery of intestinal cotransport and its application to the correct formulation and administration of oral hydration solutions was rarely sufficient to prevent many deaths from diarrhoea. Few 'grandmother solutions' were constituted adequately to tread the path of effective hydration without the hazards of hypertonicity or hypotonicity. The commonest oversight in their use was failure to ade- quately replace losses. Few family members ever thought of drinking the several gallons of soup that may be essential to replace losses in severe cases of diarrhoea.

The scientific basis for oral rehydration therapy evolved in physiology and biophysics laboratories from the late 1940 s to the early 1960 s. Of particular note were early observations from Oxford University by Parsons and Fisher who first showed in an in vitro preparation of rat small intestine that glucose enhanced the absorption of water. ${ }^{5}$ Later the biophysical laboratories of Harvard University fostered investigations of Curran ${ }^{6}$ and Crane. ${ }^{7} \mathrm{~A}$ full articulation of the obligatory transport of sodium ions with glucose molecule independent of any metabolism of glucose probably rests with Schultz and Zalusky in 1962 working at the United States Air Force School of Aerospace Medicine. ${ }^{8}$ Had the funding agencies who provided the support needed to carry out esoteric in vitro research on basic transport processes been seeking a way to alleviate death and suffering of the world's children it is unlikely they would have chosen to support the very investigations that made oral rehydration therapy possible.

Concurrently with the basic science that was in progress in England and the United States there was a resurgent interest in the problems surrounding clinical cholera. Crucial early studies by United States Naval Medical Research Units led by Captain Robert Phillips, first in Egypt in 1947 then in Thailand in 1958, led to an accurate understanding of the pathophysiology of cholera. ${ }^{9}$ This provided a firm foundation for understanding other diarrhoeal illnesses and stimulated the establishment by the United States National Institutes of Health of two research units in the midst of cholera endemic areas. One of these was The Pakistan-SEATO Cholera Research Laboratory (now The International Centre for Diarrhoeal Disease Research, Bangladesh) in Dhaka, Bangladesh. The other was the 
Johns Hopkins University International Center for Medical Research and Training in Calcutta, India. Investigators at these units were aware of current research in physiology and biochemistry and rapidly advanced understanding of cholera and related it to other diarrhoeas. ${ }^{10}$ Clinical research was linked to patient care and the situations in Dhaka and Calcutta made it obvious that although proper intravenous fluid therapy could guarantee survival of cholera patients, it was equally clear that the vast majority of patients with cholera and cholera like illnesses would never have access to intravenous technology nor be able to afford it. ${ }^{11} 12$ Thus the large numbers of untreated and dying cholera patients provided an enormous stimulus to the search for successful oral hydration solutions.

Early attempts in the Phillipines by Dr Phillips and his colleagues met with some success in showing that glucose could produce net fluid absorption in patients with cholera, but they failed because of excessive sodium concentrations in the solutions, which produced hypernatraemia. ${ }^{10}$ Careful intubation studies were then done in Dhaka to define electrical potential changes and ion fluxes produced by glucose-electrolyte solutions of varying composition perfused into actively purging cholera patients. ${ }^{13}$ Subsequently both in Dhaka and Calcutta orogastric glucose-electrolyte solutions with well defined boundaries of composition were perfused into actively purging cholera patients and it was shown that oral solutions could successfully rehydrate and maintain hydration. ${ }^{14}{ }^{15}$ In late 1967 and 1968 treatment of patients, first in the hospital and later in a rural area of Bangladesh, was successful. ${ }^{1617}$ By 1971 application of oral rehydration therapy to large numbers of victims under the most adverse conditions during the exodus of refugees from war torn Bangladesh was highly successful. Death rates of untreated cholera among refugees were between 30 and $50 \%$. With oral rehydration therapy administered by briefly trained volunteers and packaged in the library at the Johns Hopkins University International Center for Medical Research and Training in Calcutta death rates dropped to less than $3 \%$. In an area where there was medical supervision and where intravenous fluid was used for early rehydration of the most severe cases, mortality was less than $1 \% .{ }^{18}$

Investigators returning to the United States from Dhaka and Calcutta continued studies on cholera and oral rehydration therapy. In rapid succession the mechanism of action of cholera toxin was shown ${ }^{19}$ and the toxin purified. ${ }^{20}$ Other related toxins were discovered. ${ }^{21}$ The cotransporting capacity of the intestinal epithelium was shown not to be affected by any of the mechanisms producing the vast majority of diarrhoeal illness in the world. A rapid consensus was developed under the aegis of the World Health Organisation (WHO) concerning the composition of a standard solution for oral rehydration therapy. ${ }^{22}$ By 1978 the global importance of diarrhoeal diseases was recognised as WHO formed a Control Programme for Diarrhoeal Diseases $^{23}$ and the Cholera Research Laboratory in Dhaka was reconstituted as the International Centre for Diarrhoeal Diseases Research, Bangladesh. ${ }^{10} \mathrm{~A}$ concerted effort has resulted in the majority of poor countries adopting national programmes for control of deaths due to diarrhoea and diarrhoeal diseases.

With these solid accomplishments have come a series of issues including:

(1) Continuing dialogue and investigations of the safe and effective compositional boundaries of solutions being used for oral rehydration therapy. Fortunately when used early and in sufficient volumes normal renal perfusion is maintained. The resultant sustained normal renal function permits considerable latitude.

(2) The formidable practical problems of storage with timely distribution to those in need coupled with assured safe preparation remain challenging.

(3) The place of home solutions of widely varying compositions and instructions for preparation still confounds most national programmes. Thus some excellent and available oral hydration solutions are relegated to obscurity.

(4) The best way to train those who will subsequently train others to propagate the most effective use of oral rehydration therapy presents many alternatives, all of which require evaluation.

(5) Solutions with improved performance that shorten diarrhoea and improve nutrition are emerging rapidly. Decisions on how and when to advocate these in place of the now standard WHO/United Nations Childrens Fund (Unicef) oral rehydration solution present a problem.

Now in 1989 there are enormous opportunities and with these formidable challenges. Perhaps the first challenge is an urgent need to return to the basics of transport dynamics - the original source of oral rehydration therapy. We have been aware that besides glucose there are other independent cotransport pathways that have not been adequately explored. Amino acids, dipeptides and tripetides, and other compounds all depend on the sodium ion for their absorption by the gut. ${ }^{24}$ Early studies tested glycine, ${ }^{25}$ and more recently alanine has been tested in solutions for oral replacement therapy. ${ }^{26}$ It 
is clear that these and other amino acids will stimulate the transport of sodium additively to glucose at low concentrations. We need to know the theoretically optimal mix of glucose, peptides, amino acids, and any other compounds important to the transport functions and integrity of intestinal epithelium. We are lacking much of this information. Even with this knowledge, however, there is a very serious obstacle to overcome. The intestine has a very permeable or 'leaky' epithelium exquisitely sensitive to osmotic and hydrostatic forces. ${ }^{27} 28$ Thus oral rehydration solutions must be designed to have the lowest possible osmotic activity to minimise osmotic restraints to the transit of water from the lumen into the blood and lymphatics. ${ }^{29}$

The digestive system as a whole provides an extraordinary opportunity to solve the osmotic constraint. It is designed to accept polymers and degrade them at a rate and locus that minimises the accumulation of cleaved small molecules in the gut lumen. In the common diarrhoeal illnesses digestive enzymes which cleave starches and proteins are present in excess perhaps due to the hypersecretory nature of the diseases and their mediators. Thus we can present salt and water to the intestine together with cotransport molecules linked as large osmotically inactive polymers. The problem and possibility then is to define which starches and which proteins provide the best and most digestible mixture of the ultimately desired cotransporting glucose and amino acids. Or more simply stated-what foods are available locally in any situation that will best provide the needed substances to promote solute absorption? Thus science returns to the 'grandmother solutions' but with a very clear agenda in mind.

Observations from the International Centre for Diarrhoeal Diseases Research in Dhaka in 1978 that solutions for oral rehydration therapy based on rice powder were at least as effective as glucose based solutions $^{30}$ have been widely confirmed. Many studies have now shown that both the severity and duration of diarrhoea are considerably reduced and vomiting controlled by cereal based solutions. ${ }^{31} 32$ At present one field trial has been completed that appears to confirm the results of clinical trials-that there are significant advantages to cereal based solutions. ${ }^{33}$

As yet there are no studies that have looked at the kind or amount of proteins needed for optimal absorption of salt and water. It is not known how much the proteins present in the cereals contribute to the improved performance of cereal based oral rehydration solutions. This is a frontier in urgent need of exploration.

Finally it is important to emphasise that the main reason that the use of digestible polymers improves the performance of these solutions is that more cotransporting molecules can be made available with little or no osmotic penalty. Thus solutions such as rice water or other dilute starch or protein solutions for oral rehydration fail to make use of the main rationale for which a cereal based solution was introduced. Because of the fortunate finding that natural food polymers outperform commercially processed monomers there is a real risk of confusion and relapse to a potpourri of ineffective or inadequate home solutions. The principle of providing maximum cotransporting molecules at the lowest lumenal osmolality with the correct concentrations of salts and giving enough to replace all losses must be kept clearly in focus, taught effectively, and propagated without distortion for the fullest and most effective application of oral rehydration therapy.

The future holds several promises if we do our job properly. First and foremost, except under true famine conditions, all households now have cereals and salt with which effective oral rehydration solutions can be made. Communication of knowledge is needed and when successful there will be few deaths due to acute watery diarrhoea. Second it is likely that through research and the technology of the food processing industries a new family of polymeric solutions can be produced and conveniently packaged at low cost. Third it is likely that even wealthy 'developed' countries may adopt early use of oral rehydration therapy in diarrhoea and there will be great savings in the unnecessary hospitalisations now required for intravenous replacement therapy. This will reduce complications that accompany hospitalisation and indwelling vascular lines.

There will of course be many problems and controversies about how best to make use of what we know. I have entirely avoided crucial issues in the treatment of diarrhoea-that is, nutrition and what and when to feed. Implicit in what I have said about food polymers and oral rehydration therapy, however, is the fact that feeding should accelerate the resolution of diarrhoeal illnesses. This is largely true and many would say that there is no need of food based oral rehydration-we can simply use standard glucose based solutions and feed proteins and complex carbohydrates. This is in fact a viable alternative that is being explored. ${ }^{34}$ If food polymers are used for oral rehydration solutions when does one feed? My current answer is as soon as a patient is able and willing to eat. What to feed is a large area of concern and inquiry of itself. ${ }^{35}$

The special problems of treating neonates or premature babies have not been addressed in this 
discussion. How successfully oral rehydration therapy can be pressed for the treatment of the youngest infants still demands further work. That breast feeding can and should be maintained is very clear. It should be noted, however, that there may be an added margin of safety in the polymer based oral rehydration solutions. If not cleaved by digestive action the starches and proteins pass rapidly out without the hazard of osmotic diarrhoea because of their intrinsically low osmolality.

This paper was presented at the Annual Meeting of the British Paediatric Association in York, 12-15 April 1988.

\section{References}

1 Cash RA, Nalin DR, Forrest JN, Abrutyn E. Rapid correction of acidosis and dehydration of cholera with an oral electrolytes and glucose solution. Lancet 1970;ii:549-50.

2 Grant JP. The state of the world's children 1988. Oxford: Oxford University Press, 1988: 19-22. (Published for Unicef.)

3 Carpenter CCJ, Greenough WB III, Pierce NF. Oral rehydration therapy: Role of Polymeric Substrates. N Engl J Med 1988; 319:1346-8.

4 Sushruta Samhita. Vol III. Chowkamba Sanskrit Studies. Vol XXX. English translation by Kaviraj Kinjalai Bhishgrantha Chowkamba. 3rd ed. Varanasi, India: Sanskrit Sources Office, 1981.

5 Fisher RB, Parsons DS. Glucose movements across the wall of the rat small intestine. J Physiol 1953;119:210-23.

6 Curran PF. Na, $\mathrm{Cl}$, and water transport by rat ileum in vitro. J Gen Physiol 1960;43:1137-48.

7 Crane RK. Na+-dependent transport in the intestine and other animal tissues. Fed Proc 1965;24:1000-6.

8 Schultz SG, Zalusky R. Ion transport in isolated rabbit ileum II: the interaction between active sodium and active sugar transport. J Gen Physiol 1964;47:1043-59.

9 Phillips RA. Water and electrolyte losses in cholera. Fed Proc 1964;23:705-12.

10 Van Heyningen WE, Seal JR. Cholera: the American scientific experience, 1947-1980. Boulder, Colorado: Westview Press, 1983.

11 Gordon RS Jr, Feeley JC, Greenough WB III, Sprinz H, Oseasohn R. Cholera. Ann Intern Med 1966;64:1328-51.

12 Carpenter CCJ, Mondal A, Sack RB, et al. Clinical studies in Asiatic cholera II: development of 2:1 saline:lactate regimen. Comparison of this method with traditional methods of treatment April-May 1963. Bulletin of Johns Hopkins Hospital 1966;118:174-96.

13 Sachar DB, Taylor JO, Saha JR, Phillips RA. Intestinal transmural electric potential and its response to glucose in acute and convalescent cholera. Gastroenterology 1969;56:512-31.

14 Hirschhorn N, Kinzie JL, Sachar DB, et al. Decrease in net stool output in cholera during intestinal perfusion with glucosecontaining solutions. N Engl J Med 1968;279:176-81.

15 Pierce NF, Banwell JG, Mitra RC, et al. Effect of glucoseelectrolyte infusion upon water and electrolyte balance in Asiatic cholera. Gastroenterology 1968;55:333-43.
16 Cash RA, Nalin DR, Rochat R, Reller LB, Haque Z, Rahman ASMM. A clinical trial of oral therapy in a rural cholera treatment center. Am J Trop Med Hyg 1970;19:653-6.

17 Pierce NF, Sack RB, Mitra RC, et al. Replacement of water and electrolyte losses in cholera by an oral glucose electrolyte solution. Ann Intern Med 1969;70:1173-81.

18 Mahalanabis D, Choudhuri AB, Bagchi NG, Battacharya AK, Simpson TW. Oral fluid therapy of cholera among Bangladesh refugees. Johns Hopkins Medical Journal 1971;132:197-205.

19 Field M. Intestinal secretion: effect of cyclic AMP and its role in cholera. N Engl J Med 1971;284:1137-44.

20 Finkelstein RA, Lospalluto JJ. Production of highly purified choleragen and choleragenoid. J Infect Dis 1970;121(suppl): S63-72.

21 Gyles CL. Relationships among heat labile enterotoxins of Escherichia coli and Vibrio cholerae. J Infect Dis 1974;129:27783.

22 Pierce NF, Hirschhorn N. Oral fluid-a simple weapon against dehydration: how it works and how to use it. WHO Chron 1977;31:87-93.

23 Snyder JD, Merson MH. The magnitude of the global problem of acute diarrhoeal disease: a review of active surveillance data. Bull WHO 1982;60:605-13.

24 Field M. New strategies for treating watery diarrhoea. N Engl J Med 1977;297:1121-2.

25 Nalin DR, Cash RA, Rahman M, Yunus M. Effect of glycine and glucose on sodium and water absorption in patients with cholera. Gut 1970;11:768-72.

26 Wapnir RA, Zdanowicz MM, Teichberg S, Lifshitz F. Oral hydration solutions in experimental osmotic diarrhea: enhancement by alanine and other amino acids and oligopeptides. Am J Clin Nutr 1988;48:84-90.

27 Fordtran JS, Locklear TW. Ionic constituents and osmolality of gastric and small intestinal fluids after eating. American Journal of Digestive Disease 1966;11:503-21.

28 Wapnir RA, Lifshitz F. Osmolality and solute concentrationtheir relationship with oral hydration solution effectiveness: an experimental assessment. Pediatr Res 1985;19:894-8.

29 Greenough WB III. Status of cereal-based oral rehydration therapy. J Diarrhoeal Dis Res 1987;5:275-8.

30 Molla AM, Sarker SA, Hossain M, Molla A, Greenough WB III. Rice-powder electrolyte solution as oral therapy in diarrhoea due to Vibrio cholerae and Escherichia coli. Lancet 1982;i:1317-9.

31 Molla AM, Ahmed SM, Greenough WB III. Rise-based oral rehydration solution decreases the stool volume in acute diarrhoea. Bull WHO 1985;63:751-6.

32 Patra FC, Mahalanabis D, Jalan KN, Banerjee P. Is oral rice electrolyte solution superior to glucose electrolyte solution in infantile diarrhoea? Arch Dis Child 1982;57:910-2.

33 Ahmed HS, Molla AM. Rice-based oral rehydration. J Diarrhoeal Dis Res 1987;5:1-6.

34 Santosham M, Foster S, Reed R, et al. Role of soy-based, lactose-free formula during treatment of acute diarrhea. Pediatrics 1985;76:292-8.

35 Brown KB, Maclean WC. Nutritional management of acute diarrhea: an appraisal of the alternatives. Pediatrics 1984;73:119-25.

Correspondence and reprint requests to Professor WB Greenough III, Division of Geriatric Medicine, Francis Scott Key Medical Center, 5200 Eastern Avenue, Baltimore, MD 21224, USA. 